\title{
¡AYER ES NUNCA JAMÁS!: RECEPCIÓN E INFLUENCIA DE LA POESÍA DE EDGAR ALLAN POE EN ANTONIO MACHADO ${ }^{1}$
}

\author{
Cristina Flores Moreno ${ }^{2}$
}

\begin{abstract}
Resumen: Este artículo pretende mostrar la presencia de la poesía de Edgar Allan Poe en Antonio Machado, quien afirmó en "Poética" (1931) que el poeta norteamericano era uno de los padres de la poesía moderna, así como el autor del mejor poema compuesto en el siglo XIX, "The Raven". En primer lugar, abordaremos el estudio de la circulación y recepción de la poesía de Poe en España durante las primeras décadas del siglo XX, lo que nos permitirá elaborar un mapa de las diferentes rutas que le llevaron hasta Machado. Finalmente, el análisis de algunos poemas de Machado pertenecientes a Soledades y Campos de Castilla, especialmente aquellos dedicados a su joven esposa muerta, revelarán imágenes de melancolía, amor, muerte y sueños que recuerdan a Poe.

Palabras clave: E.A. Poe, poesía, recepción, influencia, Antonio Machado.
\end{abstract}

\section{Yesterday is Nevermore!: Reception and Influence of Edgar Allan Poe's Poetry on} Antonio Machado

Abstract: This paper aims at offering a picture of Edgar Allan Poe's legacy to the Spanish poet Antonio Machado, who defended in "Poética" (1931) that the American poet was one of the fathers of modern poetry as well as the author of the best poem written in the nineteenth century, "The Raven". An initial overview of the circulation and reception of Poe's poetry in Spain during the first decades of the twentieth century will help trace the different routes that took him to Antonio Machado. Finally, the analysis of some of Machado's poems in Soledades y Campos de Castilla, especially those devoted to her young departed wife, will disclose images of melancholy, love, death and dreams thar are reminiscent of Poe.

Key words: E.A. Poe, poetry, reception, influence, Antonio Machado.

El alma del poeta Se orienta hacia el misterio

Soledades, LXI

\section{INTRODUCCIÓN}

La recepción de la poesía de Edgar Allan Poe en España no fue tan inmediata como lo fue la de sus relatos cortos. En 1910, Agustín Aguilar y Francisco Ortega afirmaban en la introducción a su traducción de los poemas de Poe lo siguiente: "pocos autores extranjeros

\footnotetext{
Fecha de recepción: junio 2009.

Fecha de aceptación y versión definitiva: julio 2009.

2 Profesora Ayudante Doctor, Departamento de Filologías Modernas, Universidad de La Rioja; $\square$ cristina. flores@unirioja.es.
} 
son tan conocidos y apreciados en España como Edgar Allan Poe". ${ }^{3}$ De hecho, como es bien sabido, la historia de la recepción de Poe en este país nace en 1858 con el ensayo de Pedro Antonio de Alarcón titulado "Edgar Allan Poe. Carta a un amigo" publicado en la revista La Época, en el que se señalaba que diez o doce copias de Histories extraordinaries, la traducción al francés llevada a cabo por Baudelaire, estaban en circulación desde el año anterior. ${ }^{4}$ Los datos biográficos del autor norteamericano y sus cuentos eran por lo tanto muy conocidos a principios del siglo XX en España, principalmente gracias al esfuerzo realizado por Baudelaire, cuya traducción de los cuentos constituyó la ruta más importante a través de la cual Poe circuló en Europa durante el siglo XIX. Sin embargo, su producción poética había sido casi totalmente ignorada hasta ese momento, a excepción de "The Raven" que tras su primera publicación se convirtió en un clásico internacional en un muy breve espacio de tiempo. El poema había sido traducido y publicado en varias ocasiones durante el siglo XIX de manera individual aunque, en otras muchas ocasiones, era incluido en los volúmenes de cuentos. Como Agustín Aguilar y Francisco Ortega afirmaban en la introducción ya mencionada: "aparte de El Cuervo, la más celebre de sus obras poéticas..., son muy pocas las que en nuestro idioma conocemos" .

Sin embargo, en la primera década del siglo veinte, coincidiendo con el centenario del nacimiento del autor, surge un número notable de traducciones de sus poemas. En 1909, se publica por primera vez en España un volumen que recoge algunos de ellos: publicado en Madrid y prologado por Rubén Darío lleva el título de Poemas y contiene versiones de "The Bells", "Ullalume", "To Helen", "Dreamland", y "The Raven" (Lanero 1993:171). A éste le seguirá un año más tarde la traducción de Aguilar y Ortega. Estas traducciones, y otras más que han sido ampliamente referenciadas en Lanero, reflejan el creciente interés despertado por esta faceta de Poe que era prácticamente desconocida en España hasta ese momento. Algunos de los literatos más celebres de esta época sintieron el influjo de su obra poética. Ya en 1934, John Eugene Englekirk notó en su estudio Edgar Allan Poe in Hispanic Literature (New York: Instituto de las Españas) la presencia de Poe en Emilio Carrere, cuyos poemas en El caballero de la muerte (1909) muestran innumerables ecos de los versos de Poe, en los poemas de Francisco Villaespesa y de Juan Ramón Jiménez. Englekirk (1934: 460) sugiere también, en un breve párrafo, la gran admiración que los hermanos Manuel y Antonio Machado profesaban a E. A. Poe. En el presente trabajo, me propongo mostrar como la poesía del autor norteamericano irrumpió con fuerza y encontró su hueco en los círculos literarios españoles de principio de siglo para, posteriormente, explorar la huella que la poesía de Edgar Allan Poe dejó en los versos de uno de los más celebres poetas españoles, Antonio Machado.

Antes que yo, otros autores han considerado la presencia de Poe en el poeta español. Gurpegui (1999: 111-112) que señala, aunque sin especificar, que en la colección Soledades de Machado se puede ver un buen número de imágenes reminiscentes de Poe, hace también referencia a varios trabajos publicados previamente que analizan diversos aspectos de la

\footnotetext{
Citado en Lanero, J. J. (1993: 180). Ver Lanero (1993) para un exhaustivo estudio de las traducciones de la obra de Edgar Allan Poe en España desde 1857 hasta 1913.

4 Ver el análisis de este artículo incluido en el estudio de Santiago Rodríguez Guerrero-Strachan (1999) sobre la recepción e influencia de los cuentos de E. A. Poe en España durante el siglo XIX.

5 Citado en Lanero (1993:175).
} 
conexión existente entre los dos poetas. Se trata de los trabajos de Olivia Areti (1979), que sugiere que el frecuento uso del estribillo en Machado es resultado directo de la influencia de Poe; el de Tomás Labrador Gutiérrez (1974), en el que el autor se propone analizar hasta qué extremo las teorías poéticas de Poe se vieron reflejadas en las disquisiciones literarias de Antonio Machado; y el breve trabajo de Eugene Del Vecchio (1988) que plantea de manera muy general una serie de afinidades entre los dos autores.

Curiosamente, a excepción del trabajo de Labrador Gutiérrez, ninguno de ellos se cuestiona las posibles vías a través de las cuales Machado habría podido llegar a conocer las obras poéticas del norteamericano. Esto es probablemente debido a que se da por hecho que la principal fuente de información fueron las consabidas traducciones francesas de Baudelaire y Mallarmé. Sin embargo, Labrador Gutiérrez propone que, además de las traducciones francesas, Machado podría haber leído a Poe en su versión original ya que, según este autor, podría haber tenido el manejo de inglés necesario para ello. No obstante, este autor no considera otras posibles fuentes indirectas que pudieran proporcionarnos una visión más completa del nivel de conocimiento de Machado sobre el poeta norteamericano. Por ello considero necesario el estudio del papel jugado por su círculo de amigos escritores que con sus obras y tertulias pudieron contribuir a incrementar el interés de Antonio Machado por el autor de "The Raven". A desarrollar brevemente este aspecto dedicaré el siguiente apartado de este trabajo.

A los artículos antes mencionados, hay que añadir el recientemente publicado por Mercedes Gutiérrez García (2008) en el que demuestra la manifiesta influencia de "The Raven" en dos poemas titulados significativamente "Nevermore" y "Mai Piú" que Antonio Machado incluyó en la primera edición de Soledades, y que posteriormente no volverían a formar parte de las siguientes ediciones. El hecho de que Machado no incluyese estos poemas en ediciones posteriores de Soledades lleva a esta autora a defender que la influencia de Poe en Machado fue sólo temporal. Por el contrario, mi propuesta es que se puede argumentar razonablemente que esa influencia no se limitó a esos dos poemas en Soledades sino que es también visible en otros poemas de la colección. Además, como ya veremos más adelante, algunos poemas publicados más tarde en Campos de Castilla nos permiten observar una cierta impronta de la lírica del de Boston, lo que demuestra que la presencia de Poe en Machado fue más lejos en el tiempo de lo que hasta ahora ha sido defendido por otros autores.

\section{E. A. POE, POETA, EN EL CONTEXTO LITERARIO DE ANTONIO MACHADO}

El contexto intelectual y literario español a comienzos del siglo veinte era favorable para la recepción de la poesía de Edgar Allan Poe. Se busca la renovación poética y para ello, en parte, se retoman ciertas ideas cercanas al romanticismo. En 1902, a la pregunta de “¿Qué es el Modernismo?” Eduardo López Chavarri responde rotundamente: "una palpitación más del romanticismo" (1975: 22). El propio Antonio Machado se pregunta a sí mismo en el poema "Retrato”: “Soy clásico o romántico? No sé”. Y aunque él no

\footnotetext{
6 Todas las citas a la obra de Antonio Machado pertenecen a la siguiente edición: MACHADO, A. 1988. Poesías completas. Ed. M. ALVAR. Madrid: Espasa Calpe, Colección Austral. Desde ahora serán señaladas entre paréntesis como $P C$ seguido por el número de página y versos. Esta cita: (PC 151:21).
} 
se decante por ninguna de esas opciones, un buen número de autores, entre los que cabe destacar Doce (2005) y González (1989), han respondido para defender la vena romántica del poeta español.

Por su parte, Richard Cardwell expone los efectos provocados por la desilusión y la crisis espiritual general sentida por los hombres de letras de la época. Para este autor, una de las consecuencias principales fue: "una fuga hacia dentro buscando en el mundo interior de la imaginación un significado revelado por medio de los sueños y la duermevela o explorando y buscando en el mundo de las memorias y los recuerdos algo que resistiera el tiempo y la muerte" (Cardwell 2005:10). No es de extrañar, por lo tanto, el interés despertado por Poe que fue descrito por Rubén Darío como: "el cisne desdichado que mejor ha conocido el ensueño y la muerte" (Darío 1998: 19).

Precisamente, fue el nicaragüense Rubén Darío el mayor artífice de la introducción de Poe en España a comienzos de siglo, y quien contagió su gran interés a los hermanos Machado y a Juan Ramón Jiménez. Darío fechó su primer encuentro con Antonio Machado en 1899. A partir de entonces se sucedieron reuniones diarias en la casa de Darío a las que también asistía de manera asidua el joven Juan Ramón Jiménez, tal y como el mismo afirma: "como los Machado, y yo, y otros poetas veíamos a Darío todos los días en su casa" (Jiménez 1962: 231). Es más que probable que en esas discusiones se comentase el libro de Darío Los raros que, publicado por primera vez en Argentina en 1896, se convirtió en un libro de obligada lectura en los círculos literarios a su llegada a España en 1899. Se trata de una colección de ensayos sobre diversos autores que Darío admiraba profundamente y entre ellos se encuentra el dedicado a Edgar Allan Poe. De él dice en el capítulo introductorio: "Cada día se afirma con mayor brillo la gloria ya sin sombras de Edgar Poe" (Darío 1998: 9); y más tarde en el capítulo dedicado al poeta afirma: "La influencia de Poe en el arte universal ha sido suficientemente honda y transcendente para que su nombre y su obra sean a la continua recordados (...) desde su muerte acá, no hay año casi en que, ya en el libro o en la revista, no se ocupen del excelso poeta Americano críticos, ensayistas y poetas" (Darío 1998: 21). A pesar de que Darío adopta un enfoque biográfico y psicológico en su descripción de Poe, su lectura debió de promover un cierto interés hacia su obra. El propio Juan Ramón confesó sin reservas su admiración por Poe y reconoció en numerosas ocasiones la influencia de éste sobre su propia obra. Sirva como ejemplo la siguiente afirmación que no deja lugar a dudas: "Desde 1900 influyen en mi Rubén Darío... Baudelaire, Mallarmé (con sus poemas originales en prosa y sus magníficas traducciones de Poe que leí antes que las de Baudelaire". ${ }^{7}$ Ésta es solo una de las muchas alusiones que Juan Ramón hace a Poe. Hay que destacar la influencia notable ejercida por "The Raven": la atmósfera creada en el poema así como la imagen del cuervo aparecen frecuentemente en los poemas de Juan Ramón como, por ejemplo, en el poema “¿El cielo?” dónde se puede leer el siguiente verso "El cuervo dice: Nada más" (Pérez 1979: 225). A la vista de todo esto, no se puede sino concluir que estas reuniones con Darío y Juan Ramón, pudieron suponer una gran contribución al interés despertado en Machado por la poesía de E. A. Poe.

\footnotetext{
Citado en Carmen Pérez Romero (1980:143). Carmen Pérez Romero (1979, 1980, 1981) ha estudiado diversos aspectos de la relación entre ambos autores: desde una aproximación general, hasta el uso de los motivos del mar y el silencio.
} 
Aunque Miguel de Unamuno no asistió a esas reuniones, también pudo constituir una ruta alternativa para la recepción de Poe por Machado. Unamuno, gran conocedor de la literatura en lengua inglesa, especialmente la del período romántico, leyó con interés las obras de E. A. Poe. En su biblioteca privada se encuentra un buen número de volúmenes relacionados con el autor: un volumen de los poemas que incluye varios ensayos, tres copias de los cuentos, todos en inglés, así como las traducciones de Baudelaire y Mallarmé. Su biblioteca también alberga una traducción al francés de "The Raven", una biografía de Poe y una obra crítica sobre la presencia de E. A. Poe en la poesía francesa. ${ }^{8}$ La colección de poemas en inglés está profusamente anotada con marcas en los márgenes, lo que indica su atenta lectura. Movido por su atracción por el poeta americano, Don Miguel publicó en 1923 el ensayo "La moralidad artística" dedicado exclusivamente a la defensa de Poe contra las críticas recibidas basadas en el lado oscuro de su personalidad en lugar de centrarse en la excelencia estética de su trabajo: "El investigar de qué dolencias físicas adolecía un gran poeta o novelista es como juzgar de los descubrimientos de un hombre de ciencia por si éste sufría del hígado o del brazo. (...) El conocer las dolencias del pobre Poe (...) ha impedido a muchos ver la excelsa sanidad estética, la lucidez lógica de sus producciones. (Unamuno, IV: 1413). ${ }^{9}$ Machado y Unamuno mantuvieron una amistad profunda y duradera que permitió un intenso y fructífero intercambio de ideas a través de frecuentes encuentros personales y numerosas cartas. La gran influencia ejercida por Unamuno sobre Machado es ya un lugar común y ha sido analizada al detalle por Aurora de Albornoz (1967), aunque en este caso, cuesta definir si fue Machado el que presentó Poe a Unamuno o viceversa, o sí simplemente su admiración por Poe era otro de sus lazos de unión intelectual.

Como hemos visto, y cabía esperar, todos los autores a los que me he referido leyeron por primera vez la obra de Poe en las versiones francesas ofrecidas por Mallarmé y Baudelaire. Igualmente, eran muy conscientes de la gran contribución de Poe a la poesía francesa. Juan Ramón Jiménez, por ejemplo, notó que: "el simbolismo francés no es francés, sino una amalgama de la gran lírica inglesa con Poe americano". ${ }^{10}$ Este movimiento francés supuso indiscutiblemente una de las principales fuentes indirectas de la recepción de Poe en España y, por supuesto, en Antonio Machado que, siendo Catedrático de francés, poseía un excelso conocimiento de la lengua y literatura francesa. Su gran admiración inicial por el simbolismo francés, que llevó a Emilio Carrere a describirlo como "el grave sacerdote

\footnotetext{
The Poems of Edgar Allan Poe with a Selection of Essays (London: J.M. Dent \& Sons LTd., Everyman's Library, 1927), tres copias de Tales of Edgar Allan Poe (Leipzig: Bernhard Tauchnitz, Collection of British and American Authors, 1884), un volumen de las traducciones de los cuentos de Baudelaire (Histoires, Trad. Charles Baudelaire, Paris: La Pleiade, 1932) y la traducción de Mallarmé de los poemas (Les poèmes d'Edgar Poe. Trad. Stéphane Mallarmé. Paris: Librairie Gallimard, 1928). También se encuentra en su biblioteca privada una traducción francesa de "The Raven” realizada por A. Godoy (Le corbeau, Paris: Emile-paul, 1929). Además, su biblioteca cuenta con una biografía de Poe (L'Étrange vie et les estranges amours d'Edgar Poe, Emile Lauvrière, Paris: Desclée de Brouwer, 1934) y un estudio crítico sobre la relación entre E. A. Poe y la poesía francesa (Edgar Poe et les poètes français, Léon Lemonnier, Paris: Éditions de la Nouelle Revue Critique, 1932).

$9 \quad$ Publicado por primera vez en La Nación, Buenos Aires, el 19 de agosto de 1923. Fue escrito como respuesta a una reseña del estudio de John W. Robertson, "Edgar Allan Poe: A Psychopathic Study" (New York: G. P. Putnam's Sons, 1923) que Unamuno leyó en La Nación (Inge y Downing 1970: 5)

10 Citado en Carmen Pérez Romero (1980: 142).
} 
del simbolismo", "1 le convirtió en un perfecto receptor de la lírica del poeta de "The Raven" ya que, como Jorge Luis Borges observó, Poe fue: "padre de Baudelaire, que engendró a Mallarmé, que engendró a Valery" (1949:1). No hay duda de que el poeta español tuvo acceso a las traducciones francesas de las obras de Poe. Además, hay que decir que uno de los principales descubrimientos literarios de Machado durante su breve estancia en Paris en 1899 fue la poesía de Paul Verlain, quien también recibió un capítulo en Los raros. Machado mostró un interés particular por los Poèmes saturniens del autor francés y, muy especialmente, por uno de ellos titulado 'Nevermore', con claras reminiscencias de "The Raven", que cita al completo en Los complementarios. Este mismo poema fue, además, traducido al castellano por su hermano Manuel Machado.

\section{NEVERMORE: ESENCIALIDAD Y TEMPORALIDAD EN "POÉTICA" Y SOLEDA- $D E S$}

En 1931 Machado publicó un breve ensayo titulado "Poética" incluido, a modo de prefacio, en una antología de poesía contemporánea realizada por Gerardo Diego. En él, Antonio Machado introducía la siguiente afirmación: "el siglo lírico, (...) acentuó con un adverbio temporal el mejor poema, al par que ponía en el tiempo, (...), la ley más general de la naturaleza" (PC 81). Se refiere, claro, a "The Raven", al que alaba "por acentuar con su estribillo de 'nevermore', puesto en boca del fatídico córvido, el tema del ineludible fluir del tiempo y de la felicidad amorosa perdida para siempre" (Gibson 2006: 107). Las referencias al poeta norteamericano no acaban aquí. Previamente, en el primer párrafo de "Poética" se puede leer: "La poesía moderna, que a mi entender, arranca, en parte al menos, de Edgardo Poe, viene siendo hasta nuestros días la historia del gran problema que al poeta plantean estos dos imperativos, en cierto modo contradictorios: esencialidad y temporalidad" (PC 81-82).

Machado sentía una gran preocupación por la irreversibilidad del tiempo y su desazón por la muerte y por los efectos devastadores del paso del tiempo está presente en toda su producción poética. En sus versos, el poeta se revela ante esta fatalidad de los seres humanos por medio del poder conjurador de los sueños y la memoria, en un intento desesperado de trascender su propia temporalidad. Ribbans (2006: 148) ha señalado como una de las características principales de Machado: "un constante vaivén entre la nostalgia por emociones pasadas y las tenues esperanzas de recuperarlas". Sus poemas están impregnados de un hondo sentimiento de nostalgia por el pasado y de la angustia provocada por la certeza de que éste se haya perdido para siempre. No es de extrañar, por lo tanto, que el poeta español encontrase en el estribillo de "The Raven" la mejor expresión de una de sus angustias más profundas. Como el mismo Poe observó en "The Philosophy of Composition", el adverbio nevermore pretendía representar la melancolía, que para él constituía: "the most legitimate of all the poetical tones" (Poe 1984a: 17).

Los primeros síntomas de la presencia de Poe en Machado aparecen ya en su primera colección de poemas, Soledades, publicada en 1903. La mayoría de los poemas que com-

\footnotetext{
11 Citado en Aguirre (1973: 17). Ver el estudio de Aguirre sobre los aspectos que unen a Antonio Machado con
} el simbolismo francés. 
pletan el volumen fueron compuestos entre 1899 y 1902, coincidiendo con las frecuentes reuniones en casa de Rubén Darío, y con su estancia en París, donde conoció a Verlaine.

Como ya expuse al comienzo de este artículo, Gutiérrez García (2008) ha prestado atención a los paralelismos existentes entre "The Raven" y dos poemas de Soledades, los titulados "Nevermore" y "Mai piú" - traducción italiana de nevermore -. Ambos poemas están teñidos de melancolía, siendo el irreparable paso del tiempo su tema principal. "Nevermore" describe la visita del "¡Espíritu de ayer!" durante una "tarde vieja en el alma", que finalmente es descubierto como una mera ilusión. Machado recurre a Poe: “¡Fiesta de Abril! ... Y el eco le responde / Un nunca más, que dolorido plañe!'(PC 402: 29-33, itálicas en el original). La imposibilidad de recuperar el pasado es también el tema central alrededor del cual se construye "Mai piu". En éste, el poeta establece un contraste entre la intensa felicidad experimentada durante la mañana de un día de abril, y la tristeza que le inunda cuando, al caer la tarde, se hace patente que el momento previo de dicha ya no volverá: "La alegría / pasó por tu puerta (...) / Pasó por tu puerta. Dos veces no pasa" ( $P C$ 117: 22-23). También apunté anteriormente que el hecho de que estos dos poemas no fueran incluídos en las ediciones siguientes de Soledades ha llevado a esta autora a concluir que la influencia de Poe en Machado fue escasa y fugaz; y que su entusiasmo inicial decayó de manera gradual a lo largo de los años.

Quisiera reforzar la teoría de Gutiérrez García sobre la existencia en Machado de una fuerte atracción inicial hacia la poesía de Poe ya que, además de los dos poemas apuntados por esta autora, algunos poemas más de Soledades revelan ciertos ecos de la poesía de Poe que merecen ser señalados. Uno de los poemas de Soledades, el número LXXXV cuyo primer verso reza "La primavera besaba" (PC 143), fue seleccionado por Machado más de una década después de esa primera publicación para formar parte de Páginas Escogidas (1917). Significativamente, en esta ocasión el título de este poema pasó a ser "Nevermore", haciendo referencia a su tema central que, una vez más, es la irreversibilidad del tiempo. En sus versos, un narrador maduro medita sobre su juventud para, finalmente, concluir amargamente que no puede revivirla. En la misma línea, Machado se pregunta en "Consejos" cuando los sucesos del pasado volverán a ocurrir, pero la única respuesta posible es "Nunca Jamás":

(...) ¿cuando ha de volver

Lo que acaba de pasar?

Hoy dista mucho de ayer.

¡Ayer es Nunca Jamás! (PC 129: 3-6)

Poe afirma en "A Theory of Composition" que uno de los efectos más catastróficos del tiempo así como el motivo más poético es, indiscutiblemente, la muerte de una mujer bella. Continua Poe: "and equally it is beyond doubt that the lips best suited for such a topic are those of a bereaved lover" (Poe 1984a: 19). De hecho, un buen número de sus poemas lloran la muerte de una serie de mujeres jóvenes: Irene, Annabel Lee, Lenore,... Esto es sin duda debido a que su corta vida estuvo marcada por el fallecimiento de la mayoría de las mujeres a las que se atrevió a amar. El poeta americano se lamenta así en "A Dream within a Dream": "O God! Can I not save / One from the pitiless wave?" (Poe 1984b: 97, 
20-21). Efectivamente, da la sensación de que, en palabras de Hoffman: "Fate itself had an obsessional interest in inflicting upon poor Edgar Poe one particular species of human woe' (Hoffman 1998: 24). Dada su biografía, no nos sorprende que la muerte y el amor se convirtieran en compañeros inseparables a los ojos de Poe.

En ocasiones, Machado también recurre a esta extraña pareja. La muerte y el amor se alían en el poema de Soledades "Cante Hondo" en el que el poeta, en una imagen inicial que recuerda la primera estrofa de "The Raven", está sentado en una habitación meditando: "Yo meditaba absorto, devanando / los hilos del hastío y la tristeza" (PC 98: 1-2), cuando el silencio es roto por la música que irrumpe a través de la ventana y que es identificada como el sonido del amor y la muerte: “(...) Y era el Amor / (...) Y era la Muerte” (PC 98: $9,13)$. Ambos elementos se encuentran unidos de nuevo en el poema XII, que recuerda a los poemas que Poe dedica a la muerte de una joven mujer bella. Los labios del afligido amante lamentan la muerte de la doncella en los versos que cito a continuación:

\author{
Amada, el aura dice \\ tu pura veste blanca... \\ No te verán mis ojos; \\ ¡mi corazón te aguarda! \\ El viento me ha traído \\ tu nombre en la mañana; \\ el eco de tus pasos \\ repite la montaña ... \\ No te verán mis ojos; \\ ¡mi corazón te aguarda! \\ En las sombrías torres \\ repican las campanas ... \\ No te verán mis ojos; \\ ¡mi corazón te aguarda! \\ Los golpes del martillo \\ dicen la negra caja; \\ y el sitio de la fosa, \\ los golpes de la azada ... \\ No te verán mis ojos; \\ ¡Mi corazón aguarda! (PC 96)
}

A parte del repetitivo uso del estribillo, este poema muestra otros paralelismos con la obra poética de Poe. El viento trae noticias de la muerte de la joven que es descrita llevando un vestido blanco, que simboliza su pureza, y proyectando así una imagen similar a la de las idealizadas figuras femeninas de los poemas de Poe. El poema se compone de una serie de sonidos de muerte: las campanas, los golpes del martillo que cierran el ataúd y de la azada que cava la fosa. La campanas que promulgan el fatal destino de la joven denotan el inexorable paso del tiempo como las campanas de hierro en "The Bells", que señalan el paso del tiempo con "the melancholy meaning of the tone" (Poe 1984b: 94, 75). Ésta no es la única ocasión en la que Machado recurre al sonido de las campanas para simbolizar diferentes estadios de la vida de una persona, lo que bien podría ser considerado influencia del sonoro poema de Poe. "[L]as lágrimas sonoras/ de las campanas viejas" (PC 105: 3-4) 
que señalan el final del día y la vida en el poema XXV, contrastan con la voz de niña que suena como "una campana nueva, /como una campana virgen" $(P C, 213: 9-10)$ en un poema de Campos de Castilla sobre el que hablaremos más adelante.

Volviendo al poema XII, recordemos que en "The Raven" el pájaro de mal agüero es, así lo dice Poe, "emblematical of Mournful and Never-ending Remembrance" (Poe 1984a: 25 , itálicas en el original). El joven estudiante cree que el cuervo es un mensajero llegado para liberarle del dolor producido por sus continuos y dolorosos recuerdos de Lenore, pero recibe del pájaro una respuesta negativa. Más tarde, pregunta ansioso sobre la posibilidad de reencontrarse con su amada, pero la respuesta es, de nuevo, "Nevermore". El estribillo en el poema de Machado trasmite el mismo mensaje: la certeza de que no volverá a ver a la muchacha nunca más, -“No te verán mis ojos"-; junto con la seguridad de que seguirá recordándola y esperándola por siempre, -“¡Mi corazón aguarda!”-

\section{THE BEREAVED LOVER: CAMPOS DE CASTILLA}

En el momento en que Machado compuso el poema XII todavía no había sufrido personalmente el incalificable dolor producido por la muerte de la mujer amada. Tiene, por lo tanto, algo de premonitorio. Fue publicado algunos años antes de su primer encuentro con Leonor en 1907, cuando ella sólo contaba con doce años. Dos años más tarde, sin importarles la diferencia de edad, contrajeron nupcias en Soria. Tristemente, la joven esposa falleció tres años después como consecuencia de la tuberculosis. Machado, hundido por la desolación, llegó a confesar a Juan Ramón Jiménez que había pensado en el suicidio.

Conociendo los detalles de la vida de Edgar Allan Poe, el poeta español debió darse cuenta entonces de la sorprendente similitud existente entre los fatales destinos de Virginia y Leonor. La mujer de Poe era tan sólo un año menor que Leonor el día de su boda y murió dos años más tarde como consecuencia de la misma enfermedad. En estas circunstancias, Machado debió de sentir cierta empatía hacia el autor americano, cuyos poemas seguramente adquirieron un nuevo y más intenso significado para el desdichado viudo. No hay duda de que en esos momentos la lectura del poema "Lenore" dedicado a una joven que acaba de fallecer, -“the spirit flown forever! / Let the bell toll!"” (Poe 1984b: 68, 1-2) -, pudo haber ejercido una fuerte impresión en Machado. ${ }^{12}$ En el poema, se pide el canto de: "An anthem for the queenliest dead that ever died so young / A dirge for her the doubly dead in that she died so young" (1984b: 6-7), en unos versos que enfatizan la juventud e inocencia de la dama, características que fácilmente pudieron recordarle a su querida Leonor. Recordemos igualmente, que la joven desaparecida en "The Raven" comparte el mismo nombre.

Tras la desaparición de su esposa, Machado publicó una segunda edición de Campos de Castilla $^{13}$ en la que incluía un grupo de poemas dedicados a ella. Estos poemas, compuestos durante al año que siguió al triste fallecimiento de Leonor, reflejan una abanico de emociones que van desde al angustia, soledad y resignación hasta la esperanza. El poeta llora su muerte en versos como “¡Ay, ya no puedo caminar con ella!” (PC 212) o "Señor,

\footnotetext{
12 Hay que recordar que en esta fecha Machado contaba, además de con la traducción francesa de los poemas de E. A. Poe, con varias traducciones al castellano que ya estaban disponibles en las librerías.

13 La primera edición fue publicada en 1912, poco antes de la muerte de Leonor. En 1917, en la primera edición de Poesías completas, Machado incrementó Campos de Castilla en 46 poemas.
} 
ya me arrancaste lo que yo más quería" (PC 212); y en ellos libra una continua lucha entre la ilusión y la desesperanza ${ }^{14}$.

En los sueños encuentra su mejor aliado, ya que sólo a través de ellos puede convertir en presente los tiempos ya pasados. En este ámbito, Machado no concibe el sueño como el vehículo que le trasporte a mundos imaginarios y fantásticos para así evadirse de la realidad que le atormenta, sino como un medio de viajar hacía atrás en el tiempo. Para el poeta, los sueños son "retablos de esperanzas y recuerdos" ${ }^{15}$ que recrean la realidad pasada y devuelven a la vida a los ya desaparecidos. Cierto paralelismo puede ser establecido con E. A. Poe, quien en su poema "Dream-Land" nos muestra que los sueños son el lugar donde se pueden evocar a los muertos y encontrarse con ellos. Así, en uno de sus más populares poemas, la luna le trae sueños de la bella Annabel Lee de manera que puede contemplar de nuevo los brillantes ojos de la dama. También Leonor retorna a la vida a través de los sueños del poeta. En los versos, la joven sigue hablando con voz de niña, y caminando de la mano de su marido:

[M]i corazón está vagando, en sueños ...

¿No ves, Leonor, los álamos del río

Con sus ramajes yertos?

Mira el Moncayo azul y blanco; dame

Tu mano y paseemos. $(P C, 21: 6-10)$

Las campanas que otrora sonaban fúnebres, tocan ahora sonidos nuevos en el poema CXXII. La voz de la muchacha suena como las campanas de plata en el poema de Poe "The Bells", que inauguran una vida nueva. La presencia en sueños de Leonor se le antoja real al poeta:

Soñé que tú me llevabas

por una blanca vereda

(...)

Sentí tu mano en la mía,

tu mano de compañera,

tu voz de niña en mi oído

como una campana nueva,

como una campana virgen

de un alba de primavera.

¡Eran tu voz y tu mano,

en sueños, tan verdaderas! ...(PC 213: 1-2, 7-14)

El momento preciso de la muerte de Leonor es recreado por Machado en el poema CXXIII, que podría haber sido inspirado por el poema de Poe "The Sleeper" dadas las similitudes entre ambos. Estos poemas nos presentan sendas mujeres jóvenes, yaciendo

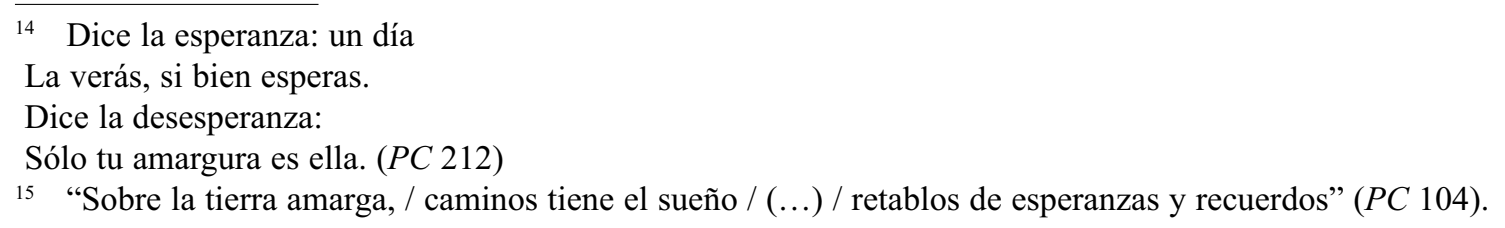


en la cama, rodeadas de imágenes de muerte. Merece la pena citar el poema completo del poeta español:

Una noche de verano

- estaba abierto el balcón

y la puerta de mi casa -

la muerte en mi casa entró.

Se fue acercando a su lecho

- ni siquiera me miró -,

con unos dedos muy finos,

algo muy tenue rompió.

Silenciosa y sin mirarme,

la muerte otra vez pasó

delante de mí. ¿Qué has hecho?

La muerte no respondió.

Mi niña quedó tranquila,

dolido mi corazón.

¡Ay, lo que la muerte ha roto

Era un hilo entre los dos! (PC 213-4)

La acción en ambos poemas se sitúa en una noche cálida, una noche de verano en el poema de Machado y "At midnight, in the month of June" (Poe 1984b: 64,1) en el de Poe. Las dos jóvenes están tumbadas en sus lechos de muerte: Irene, en "The Sleeper”, ya está muerta mientras que Leonor está a punto de exhalar su último aliento. La calma de la habitación es perturbada por imágenes de muerte que irrumpen en la habitación a través de un balcón abierto, en Machado, y a través de una "window open to the night" (1984b: 65, 18-19) en "The Sleeper". Mientras, las dos jóvenes se muestran impasibles, silenciosas, no dan señal alguna de miedo o de cualquier otra emoción. Karen Weekes (2009) ha argumentado que las mujeres de Poe, especialmente en sus poemas, sirven al único propósito de inspirar la melancolía del narrador. Según lo ve esta autora, son receptáculos de la rabia del narrador, ellas pasan el umbral de la muerte silenciosamente, sin manifestar ningún sentimiento al respecto. Esta es la imagen de mujer que nos encontramos tanto en "The Sleeper" como en los poemas que Machado dedica a Leonor.

\section{CONCLUSIONES}

En vista de todo lo anterior, podemos concluir que la fascinación de Antonio Machado por la poesía de Poe nació de su estudio de literatura francesa y fue altamente estimulada gracias a sus reuniones frecuentes con Rubén Darío y Juan Ramón Jiménez, así como por su estrecha amistad con Miguel de Unamuno. Su tendencia innata hacia la melancolía también contribuyó a su atracción por la poesía de Poe, quien confiesa en "Introduction": "I fell in love with melancholy" (Poe 1984b: 54, 28); y muy especialmente por "The Raven", que encuentra ecos obvios en Soledades, la primera colección de poemas del poeta español. El recurrente sentimiento de nostalgia en Machado creció enormemente con la muerte de su joven esposa. Este episodio quizá le hizo volver a los poemas de Poe que le legaron 
imágenes de amor y muerte que adoptó y adaptó en los versos que dedicó a Leonor en la segunda edición de Campos de Castilla. Como hemos visto, la lectura atenta de esos versos revela paralelismos con otros poemas de Poe como "The Bells" y "The Sleeper".

Sin duda sería necesario un estudio más amplio de la obra poética de Antonio Machado para llegar a conocer el verdadero alcance de la presencia de Edgar Allan Poe. En este trabajo se ha constatado que la influencia del americano en el poeta español no fue tan efímera como algunos autores han propuesto. De hecho, es importante subrayar que las afirmaciones en las que Machado señala a "The Raven" como el mejor poema del siglo lírico y en la que identifica a Poe como uno de los fundadores de la poesía moderna, fueron realizadas por Machado en 1931, en su etapa madura, a sólo siete años de su fallecimiento. Se trata por lo tanto de una reflexión largamente meditada. Podríamos decir que la presencia de Poe en Machado fue profunda y duradera. No en vano, el gran poeta español encontró en la poesía de Poe la mejor expresión para una de sus preocupaciones más acuciantes, la irreversibilidad del tiempo, que articulo así en algunos de sus versos más celebrados:

$\mathrm{Al}$ andar se hace camino, y al volver la vista atrás se ve la senda que nunca se ha de volver a pisar. (PC 239)

\section{REFERENCIAS BIBLIOGRÁFICAS}

Aguirre, J. M. 1973. Antonio Machado, poeta simbolista. Madrid: Taurus.

Albornoz, A. 1967. La presencia de Miguel de Unamuno en Antonio Machado. Madrid: Gredos.

Areti, O. 1979. “Antonio Machado e la poetica di E. A. Poe'. Studi Ispanici: 131140.

Borges, J. L. "Edgar Allan Poe". La Nación. 2 de octubre de 1949, Buenos Aires: Segunda Sección: 1.

Bynum, B. B. 1993. The Romantic Imagination in the Works of Gustavo Adolfo Bécquer. Chapel Hill: The University of North Carolina.

CARDwell, R. 2005. "Juan Ramón Jiménez y el Modernismo: una nueva visión de conjunto". Ínsula 705: 9-12.

CERezo, P. 1975. Palabra en el tiempo. Poesía y filosofía en Antonio Machado. Madrid: Gredos.

DARío, R. 1998. Los raros. Zaragoza: Libros del Innombrable.

Doce, J. 2005. Imán y desafio. Presencia del romanticismo inglés en la poesía española contemporánea. Barcelona: Península.

Englekirk, J. E. 1934. Edgar Allan Poe in Hispanic Literature. New York: Instituto de las Españas. 
García, J. M. 1995. “Los raros de Rubén Darío: 'Edgar Allan Poe', foto-síntesis de una máquina reproductora'. Cuadernos para investigación de la literatura hispánica 20: $189-196$.

Gibson, I. 2006. Ligero de equipaje. La vida de Antonio Machado. Madrid: Aguilar.

GonzÁLEz, A. 1989. “Antonio Machado y la tradición romántica”. En torno a Antonio Machado. Ed. F. LÓPEZ. Madrid: Júcar. 37-54.

Gurpegui, J. A. 1999. "Poe in Spain". Poe Abroad. Influence, Reputation, Affinities . Ed. L. D. VINES. Iowa City: University of Iowa Press. 108-114.

Gutierrez, M. 2008. “'El cuervo' de E. A. Poe en 'Nevermore’ y 'Mai piú', dos poemas de Antonio Machado”. Crítica Hispánica 30, 1-2: 55-68.

Hoffman, D. 1998. Poe, Poe, Poe. Louisiana: Louisiana State University Press, Baton Rouge.

Inge, T. M. and G. Downing. 1970. "Unamuno and Poe". Poe Newsletter III, 2: 35-6.

JimÉneZ, J. R. 1962. El modernismo. Notas de un curso. Eds. R. Gullón y E. FernánDEZ. Madrid: Aguilar.

Labrador, T. 1974. "Presencia de Edgar Allan Poe en Antonio Machado". Archivo Hispalense 57, 157: 87-119.

Lanero, J. J., J. C Santoyo and S. Villoria. 1993. "50 años de traductores, críticos e imitadores de Edgar Allan Poe (1857-1913)”. Livius 3: 159-184.

LÓPEZ, E. 1975. “QQué es el Modernismo”. El Modernismo. Ed. L. LITVAK, Madrid: Taurus.

Machado, A. 1988. Poesías completas. Ed. M. Alvar. Madrid: Espasa Calpe, Colección Austral.

PÉrez, C. 1979. "Raices Norteamericanas en la obra de Juan Ramón Jiménez: E. A. P. y la poesía Juanramoniana". Anuario de estudios filológicos 2: 211-229.

1980. "El mar de E. A. Poe y su repercusión en Juan Ramón Jiménez". Anuario de estudios filológicos 3: 141-152.

. 1981. “La concepción de 'silencio' de E. A. Poe y su eco en la poesía de Juan Ramón Jiménez”. Atlantis 3, 1: 69-77.

Poe, W. A. 1984a. Essays and Reviews. New York: The Library of America. 1984b. Poetry and Tales. New York: The Library of America.

RibBAns, G. 2006. “Antonio Machado: de los 'paisajes del alma' al 'alma de paisaje"”. Hoy es siempre todavía. Curso internacional sobre Antonio Machado. Ed. J. DoMÉNECH. Sevilla: Renacimiento. 139-172.

Rodríguez, S. 1999. Presencia de Edgar Allan Poe en la literatura española del siglo $X I X$. Valladolid: Secretariado de Publicaciones e Intercambio Científico Universidad de Valladolid. 
Unamuno, M. de. 1966. Obras Completas. Madrid: Escelicer

Vecchio, E del. 1988. "E. A. Poe and Antonio Machado: An Undetected Affinity". Discurso Literario 5.2: 395-400.

Vines, L. D. Ed. 1999. Poe Abroad: Influence, Reputation, Affinities. Iowa: University of Iowa Press.

Weekes, K. 2009. "Poe's Feminine Ideal”. The Cambridge Companion to Edgar Allan Poe. Ed. Hayes, K. J. Cambridge: Cambridge University Press. 148-162. 